\title{
Agreement Between Echocardiogram and Right Heart Catheterization in the Daily Practice of Investigation of Pulmonary Hypertension
}

\section{Camila Farnese Rezende}

Hospital das Clinicas da Universidade Federal de Minas Gerais https://orcid.org/0000-0003-1043-6054

Eliane Viana Mancuzo

Hospital das Clinicas da Universidade Federal de Minas Gerais

Maria Carmo P Nunes

Hospital das Clinicas da Universidade Federal de Minas Gerais

Ricardo de Amorim Corrêa ( $\square$ racorrea9@gmail.com )

Hospital das Clinicas da Universidade Federal de Minas Gerais https://orcid.org/0000-0003-1779-0443

\section{Research Article}

Keywords: Diagnosis, hemodynamics, pulmonary hypertension, pulmonary artery systolic pressure, right atrium pressure

Posted Date: July 30th, 2021

DOl: https://doi.org/10.21203/rs.3.rs-738879/v1

License: (9) This work is licensed under a Creative Commons Attribution 4.0 International License. Read Full License 


\section{Abstract}

Purpose: Studies in the context of research have shown a significant disagreement between the echocardiographic measurement of the systolic pulmonary artery pressure (sPAP) and right atrial pressure (RAP) and that obtained by right heart catheterization (RHC). We compare measurements of SPAP and RAP, verified by transthoracic echocardiogram (TTE) with those detected by RHC in patients being investigated for pulmonary hypertension $(\mathrm{PH})$.

Methods: Cross-sectional study was performed in a context of usual clinical practice in the public referral center for $\mathrm{PH}$, including patients with high or intermediate echocardiographic probability of pulmonary arterial hypertension and chronic thromboembolic PH. Bland-Altman test was used to assess the agreement amongthe values and ROC curve to identify SPAP and tricuspid regurgitation velocity (TRV) values with better accuracy. Clinically acceptable differences of $10 \mathrm{mmHg}$ for SPAP and $5 \mathrm{mmHg}$ for RAP were considered.

Results: Ninety-five patients were included. The Bland-Altman analysis showed a bias of $8.03 \mathrm{mmHg}$ for SPAP and $-3.30 \mathrm{mmHg}$ for RAP. Area under the curve for SPAP and TRV measured by TTE were $0.936(95 \%$ Cl: 0.836-1.0) and 0.919(95\% Cl: 0.837-1.0), respectively. According to the pre-defined pressure differences, only $33.4 \%$ of the echocardiographic estimate of SPAP and $55.1 \%$ of RAP were accurate, as compared to the measurements obtained by RHC.

Conclusions: Real life study revealed that echocardiographic evaluation demonstrated a high discriminatory power for diagnosis of PH, but SPAP and RAP measurements showed significant disagreements in relation to hemodynamic measures. The technical improvement of diagnostic services may contribute to the earlier recognition of this condition by TTE.

\section{Introduction}

Pulmonary hypertension $(\mathrm{PH})$ is characterized by an increased pulmonary arterial resistance, and it is currently defined by the presence of mean pulmonary artery pressure (mPAP) higher than $20 \mathrm{mmHg}$ and pulmonary vascular resistance (PVR) higher than or equal to $3 \mathrm{UW}$, as directly measured in the pulmonary artery by right heart catheterization (RHC) [1]. This condition causes increased afterload of the right ventricle, resulting in hypertrophy, cavity dilation with reduction in contractility, which ultimately lead to right-sided heart failure and death. $\mathrm{PH}$ represents a factor of worse prognosis, although with variable survival time, depending on the underlying disease $[1,2]$. The recommended diagnostic procedures aim at detecting the associated conditions for which specific therapeutical measures should be indicated. A transthoracic echocardiogram (TTE) should be performed in all clinically suspected cases of PH. Among the data obtained, the tricuspid regurgitation maximal velocity (TRV) and, subsequently, the estimated systolic pulmonary artery pressure (SPAP) constitute essential parameters for confirmation of the suspected condition, being criteria taken into consideration for recommendation of a $\mathrm{RHC}[3,4]$. 
Studies made in the context of research protocols have shown a significant disagreement between the echocardiographic measurement of the SPAP and that obtained by RHC, resulting in either underestimation or overestimation of such measurements. This leads to difficulties in the diagnosis of $\mathrm{PH}$ and consequent delays in its management [5-7]. However, the magnitude and direction of such disagreement have not been verified within the context of the usual clinical practice of $\mathrm{PH}$ diagnosis. For this specific analysis, observational or pragmatic assessments have been used to evaluate the accuracy of different methods for $\mathrm{PH}$ assessment in the usual clinical practice, aiming at achieving more representative data in a non-strictly selected population $[8,9]$.

This study was design to assess the agreement between initial measurements of SPAP and right atrial pressure (RAP) made by both TTE and RHC in patients referred for PH evaluation in clinical practice of the Brazilian National Health System (Sistema Único de Saúde-SUS) for diagnosis of PH prior to the beginning of the specific treatment.

\section{Methods}

\section{Study population}

It is a cross-sectional study involving patients referred for the Pulmonary Circulation Unit of Hospital das Clínicas of the Federal University of Minas Gerais (HC/UFMG), a local PH reference center, in Belo Horizonte, Minas Gerais, in the period from September, 2004 to April, 2015.

It includes all 18-year-old or older patients, who were evaluated in an ambulatory basis, and had a clinical and laboratory suspicion of pulmonary arterial hypertension (PAH) or chronic thromboembolic pulmonary hypertension (CTEPH), a high or intermediate probability by TTE of pulmonary hypertension and who underwent $\mathrm{RHC}$ to confirm diagnosis. A maximum 6-month interval was established between the TTE and the RHC.

Patients with diagnosis of $\mathrm{PH}$ due to left heart disease (group 2), associated with pulmonary diseases and/or hypoxemia (group 3) and with unclear and/or multifactorial mechanisms (group 5) were not eligible for this study, since RHC is not usually indicated for the diagnosis of patients with pre-defined criteria for these $\mathrm{PH}$ groups [1, 3].

This study was approved by UFMG's Research Ethics Committee (ETIC nr. 1.057.219/2015), and all participants who agreed to participate signed the Term of Informed Consent.

\section{Echocardiography and right heart catheterization}

TTE and RHC examinations were requested according to the protocol and performed in health care units authorized by SUS's municipal public system.

The evaluation by TTE took into consideration echocardiographic variables suggestive of $\mathrm{PH}$, the peak of TRV, the RAP and the sPAP, estimated by the modified form of Bernoulli's equation: SPAP $=4 T R T^{2}+$ RAP. 
The RAP was estimated during the inspiratory maneuver as follows: for diameter of the inferior vena cava (IVC) smaller than $2.1 \mathrm{~cm}$ associated with its collapse $>50 \%$, estimated RAP $=3 \mathrm{mmHg}(0-5 \mathrm{mmHg})$; for diameter of the IVC larger than $2.1 \mathrm{~cm}$ with its collapse $<50 \%, \mathrm{RAP}=15 \mathrm{mmHg}(10-20 \mathrm{mmHg})$. An intermediate value of $8 \mathrm{mmHg}(5-10 \mathrm{mmHg})$ was used when these criteria were not met $[4,10]$.

Other echocardiographic parameters suggestive of $\mathrm{PH}$ were the presence in at least two of the following three categories: the ventricles (right ventricle/left ventricle basal diameter ratio $>1$ and/or flattening of the interventricular septum); the pulmonary artery (acceleration time in the pulmonary artery $<105 \mathrm{~ms}$ and/or increased pulmonary regurgitation velocity $>2.2 \mathrm{~m} / \mathrm{sec}$ and/or increased diameter of pulmonary artery $>25 \mathrm{~mm}$ ); and the IVC and right atrium (diameter of the IVC larger than $2.1 \mathrm{~cm}$ associated with its collapse $<50 \%$ and/or area of the right atrium $\left.>18 \mathrm{~cm}^{2}\right)[1,3-4,10]$.

The probability of being diagnosed with $\mathrm{PH}$ was considered high in patients presenting TRV $>3.4 \mathrm{~m} / \mathrm{s}$ or TRV between 2.9 and $3.4 \mathrm{~m} / \mathrm{s}$ with other echocardiographic signs. This probability was considered intermediate when the TRV was between 2.9 and $3.4 \mathrm{~m} / \mathrm{s}$ with no other signs, or TRV $\leq 2.8 \mathrm{~m} / \mathrm{s}$ with other additional signs [1]. These data were obtained from SUS's database, medical records and examination results.

Diagnosis of PH was confirmed when RHC done in the HC-UFMG found a mPAP equal to or higher than $25 \mathrm{mmHg}$ at rest, based on the international guidelines at the time of this study [3]. Briefly, RAP $(\mathrm{mmHg})$, SPAP $(\mathrm{mmHg})$ and mPAP $(\mathrm{mmHg})$ and PAWP (pulmonary arterial wedge pressure, $\mathrm{mmHg}$ ) were recorded at the end of a normal expiration. Cardiac output $\left(\mathrm{CO}, \mathrm{L} / \mathrm{min}^{-1}\right)$ was calculated based on the indirect Fick method, which estimates the oxygen uptake $(\mathrm{VO} 2, \mathrm{ml} / \mathrm{min})$ and the cardiac index $\left(\mathrm{Cl}, \mathrm{L} \cdot \mathrm{min}^{-1} \cdot \mathrm{m}^{-2}\right)$ should be calculated as the ratio of $\mathrm{CO}$ to body surface area. The PVR was calculated as PVR $=$ (mPAPPAWP)/CO. All measurements were obtained with reference to the zero level at the mid-thoracic line [11].

\section{Statistical analysis}

Data distribution has been established according to the Shapiro-Wilk test. This way, data have been presented as frequency and percentage, mean (standard deviation) or median (interquartile range). The agreement of values between the RHC and the TTE has been analyzed by the Bland-Altman plot and the coefficients of variation (CV) and repetition (CR) [12-14]. The estimated bias (average of differences in the measurements of SPAP and RAP between the TTE and the RHC) and its standard deviation (SD) and the $95 \%$ agreement limits have been calculated for preparation of the Bland-Altman plot $[12,13]$. This method evaluates the measurement error, calculated by dividing the standard deviation of the average differences by the square root of two [14]. The CV is a dispersion measurement that describes the amount of data variability related to the mean, and it has been calculated by the formula: $C V=S D$ of the average difference of the measurements made by TTE and by RHC / mean of the averages of these measurements multiplied by 100 [13]. The CR shows the expected variation of the results for $95 \%$ of the repeated measurements, calculated as follows: $C R=S D$ of the average difference of the measurements made by TTE and by RHC multiplied by 1.96 [12]. 
The ROC curve was used to determine SPAP and TRV cut-off values for the diagnosis of PH. Differences of $5 \mathrm{mmHg}$ for RAP and $10 \mathrm{mmHg}$ for SPAP between the TTE and the RHC were considered as clinically acceptable [5].

The sample power has been calculated by the paired t-test to allow evaluation of the agreement of the sPAP measurements between the TTE and the RHC, by using the Minitab Release 14 statistical package. The sample from 90 patients obtained an $80 \%$ statistical power in the estimate of the actual difference in the SPAP measurements between the TTE and the RHC, assuming a clinically acceptable difference of $10 \mathrm{mmHg}$, with a significance level of 0.05. A $p$ level lower than 0.05 was considered significant for all the analyses. This analysis has been made in the Statistical Package for the Social Sciences, SPSS18.

\section{Results}

Ninety-five patients were consecutively admitted in the HC/UFMG reference center and met the inclusion criteria in the study period. One patient was excluded because it was not possible to retrieve the SPAP and RAP measurements from the TTE preceding the RHC. Five patients had no confirmed diagnosis of PH by RHC. The mean age was $47.6 \pm 14$.5years old (range from 18 to 79 years old), most of them $(69.4 \%)$ women and in functional class III (42.1\%). Fifty-six patients (62.9\%) were diagnosed with PAH and 33 (37.1\%) with CTEPH. No patient was being submitted to specific therapy for $\mathrm{PH}$ at the time of the examinations (Table 1). 
Table 1

Demographic, Clinical, Doppler Echocardiography and Hemodynamic Characteristics of the Study Population $(n=95)$

\begin{tabular}{|ll|}
\hline Age, mean \pm SD, $y$ & $47.6 \pm 14.5$ \\
\hline Women, $n(\%)$ & $66(69.4 \%)$ \\
II NYHA, $n(\%)$ & $8(8.4 \%)$ \\
III & $37(38.9 \%)$ \\
IV & $40(42.1 \%)$ \\
\hline PH prevalence & $10(10.5 \%)$ \\
No PH, $n(\%)$ & \\
PH, $n$ (\%) & $5(5.2 \%)$ \\
Interval between noninvasive and invasive measurement, median (IQR), days & $90(94.8 \%)$ \\
PAH, $n$ (\%) & $104(62-153)$ \\
Schistosomiasis & $56(62.9 \%)$ \\
Idiopathic & $19(33.9 \%)$ \\
Congenital heart disease & $14(25 \%)$ \\
Connective tissue disease & $9(16.1 \%)$ \\
Portopulmonary hypertension & $8(14.8 \%)$ \\
HIV & $4(7.1 \%)$ \\
CTEPH - $n$ (\%) & $2(3.6 \%)$ \\
\hline
\end{tabular}

Data are given as mean \pm SD or median (IQR: interquartile range). Cl: cardiac index; CTEPH: chronic thromboembolic pulmonary hypertension; FC: functional class (New York HeartAssociation); HIV: human immunodeficiency virus; mPAP: mean pulmonary arterial pressure; $\mathrm{PAH}$ : pulmonary arterial hypertension; PAWP: pulmonary arterial wedge pressure; PH: pulmonary hypertension; PVR: pulmonary vascular resistance; sPAP: systolic pulmonary arterial pressure; RAP: right atrial pressure; TAPSE: tricuspid annular plane systolic excursion; TRV: tricuspid regurgitation velocity. 


\section{Transthoracic echocardiogram}

$\mathrm{SPAP}$, mean $\pm \mathrm{SD}, \mathrm{mmHg}$

$79.9 \pm 24.7$

$\mathrm{RAP}$, mean $\pm \mathrm{SD}, \mathrm{mmHg}$

$12.9 \pm 4.7$

$T R V$, mean $\pm S D, m / s$

$3.78 \pm 0.71$

TAPSE, median (IQR), mm

$16(15-18)$

Pericardial effusion, $\mathrm{n}(\%)$

$11(12 \%)$

\section{Right heart catheterization}

$\mathrm{sPAP}$, mean $\pm \mathrm{SD}, \mathrm{mmHg}$

$87.6 \pm 27.2$

mPAP, mean $\pm S D, m m H g$

$70.2 \pm 14.4$

$\mathrm{RAP}$, mean $\pm \mathrm{SD}, \mathrm{mmHg}$

$9.6 \pm 5.6$

PAWP, median (IQR), $\mathrm{mmHg}$

$10.0(9.2-12.4)$

$\mathrm{Cl}$, median (IQR), L. $\mathrm{min}^{-1} \cdot \mathrm{m}^{-2}$

PVR, median (IQR), Wood units

$6.6(5.1-8.2)$

Data are given as mean \pm SD or median (IQR: interquartile range). Cl: cardiac index; CTEPH: chronic thromboembolic pulmonary hypertension; FC: functional class (New York HeartAssociation); HIV: human immunodeficiency virus; mPAP: mean pulmonary arterial pressure; PAH: pulmonary arterial hypertension; PAWP: pulmonary arterial wedge pressure; PH: pulmonary hypertension; PVR: pulmonary vascular resistance; sPAP: systolic pulmonary arterial pressure; RAP: right atrial pressure; TAPSE: tricuspid annular plane systolic excursion; TRV: tricuspid regurgitation velocity.

The data from the TTE and from the RHC are described on Table 1. In the TTE, the mean SPAP was 79.9 $\pm 24.7 \mathrm{mmHg}$ and the RAP was $12.9 \pm 4.7 \mathrm{mmHg}$, whereas SPAP and RAP was $87.6 \pm 27.2 \mathrm{mmHg}$ and $9.6 \pm$ $5.6 \mathrm{mmHg}$, respectively, in the RHC.

A statistically significant bias was verified between both examinations regarding the SPAP measurement $(8.0 \pm 21.9 \mathrm{mmHg})$, as shown in Fig. 1. Regarding the agreement parameters (Table 2), the measurement error was of $15.5 \mathrm{mmHg}$, the CV was of $26 \%$ and the $\mathrm{CR}$ was of $42.9 \mathrm{mmHg}$. 
Table 2

sPAP and RAP Measurements on Transthoracic Echocardiogram and Right Cardiac Catheterization and their Reproducibility

\begin{tabular}{|lll|}
\hline Variables & SPAP & RAP \\
\hline Average of measurements in TTE, mmHg & $79.9 \pm 24.7$ & $12.9 \pm 4.7$ \\
\hline Average of measurements in $\mathrm{RHC}, \mathrm{mmHg}$ & $87.6 \pm 27.2$ & $9.6 \pm 5.6$ \\
\hline Average of differences, $\mathrm{mmHg}$ & $8.0 \pm 21.9$ & $-3.3 \pm 6.4$ \\
\hline $95 \%$ agreement limits $(\mathrm{mmHg})$ & -34.9 to 50.9 & -15.9 to 9.3 \\
\hline Measurement error $(\mathrm{mmHg})$ & 15.5 & 4.6 \\
\hline Coefficients of variation $(\%)$ & 26 & 57 \\
\hline Coefficients of repetition $(\mathrm{mmHg})$ & 42.9 & 12.7 \\
\hline $\begin{array}{l}\text { Data are given as mean } \pm \text { SD. sPAP: systolic pulmonary arterial pressure; RAP: right atrial pressure; } \\
\text { RHC: right heart catheterization; TTE: transthoracic echocardiogram. }\end{array}$ \\
\hline
\end{tabular}

Figure 2 and Table 2 show the agreement parameters between the RAP measurements in the TTE and in the RHC, with a significant bias of $-3.3 \pm 6.4 \mathrm{mmHg}$ (95\% IC:-15.9 to 9.3 ).

The ROC curve presented a high discriminatory power, with area under the curve of 0.936 (95\%IC: 0.84 1.0) for SPAP and of 0.919 (95\%IC: $0.84-1.0$ ) for TRV, measured by the TTE, and cut-off point of $48 \mathrm{mmHg}$ (sensitivity $=0.907$, specificity $=1.0$, negative predictive value $(N P V)=0.286$ and positive predictive value $(P P V)=1.0$ ) and $3.075 \mathrm{~m} / \mathrm{s}$ (sensitivity $=0.907$, specificity $=1.0, \mathrm{NPV}=0.333$ and $P P V=1.0$ ), respectively, for diagnosis of $\mathrm{PH}$ (Fig. 3).

By using the definition of measurement accuracy for SPAP (variation up to $10 \mathrm{mmHg}$ ) and RAP (variation up to $5 \mathrm{mmHg}$ ) in the TTE compared to the RHC, only $55.1 \%$ of the estimates of RAP and $33.4 \%$ of the estimates of SPAP were accurate (Fig. 4). TTE underestimated the SPAP values by $41.5 \%$ versus $25.1 \%$ $(-30.4 \pm 10.2$ versus $15.2 \pm 8.9 \mathrm{mmHg} ; p=0.04)$ and overestimated the RAP values by $33.7 \%$ versus $11.2 \%$ $(11.3 \pm 4.8$ versus $-8.4 \pm 3.7 \mathrm{mmHg} ; p=0.03)$ in cases with difference above the clinically acceptable one. An illustration of echocardiographic evaluation of estimated SPAP and RAP in a patient with schistosomiasis associated pulmonary arterial hypertension and the difference of these measurements in the RHC are provided in Fig. 5.

\section{Discussion}

This study including patients with suspected $\mathrm{PH}$ referred to a referral care centre, echocardiographic evaluation demonstrated a high discriminatory power for diagnosis of $\mathrm{PH}$. Compared with the goldstandard invasive method, there are disagreements between SPAP and RAP measurements, which is similar to the results of other studies within controlled research contexts [5-7]. 
The diagnostic threshold of mPAP for the definition of chronic $\mathrm{PH}$ has been lowered from $\geq 25 \mathrm{mmHg}$ to $>20 \mathrm{mmHg}[1,15]$. This change is based on an increasing body of evidence demonstrating that even mild elevations of pressure have prognostic value. Echocardiography remains the most appropriate approach for the prediction of PH. Gall and colleagues affirm that decreasing the lower limit of TRV does not improve the diagnostic yield of echocardiography for $\mathrm{PH}$ and provides key evidence reinforcing the clinical value offered by composite echocardiographic parameters in patients inclusive of mild PH [15].

The population presented in this study represents all patients evaluated at the referral center Pulmonary Circulation Unit of Hospital das Clínicas of Federal University of Minas Gerais who were indicated to undergo RHC for diagnosis of PAH and CTEPH consecutively in the period of this study. The sample had a larger number of patients with PAH (62.9\%) than those with CTEPH (37.1\%). Differently from the international reports, schistosomiasis was the most prevailing etiology, as already expected [16-19]. It results from the high prevalence of schistosomiasis in some regions of Brazil, particularly in the state of Minas Gerais, where its occurrence is endemic [20]. The average age of the patients and most of them being women, similarly to the available records from other countries, suggests that this prevalence does not depend on location and gender $[18,19]$. Similarly to international reports, most of the patients were in FC III and IV (52.6\%), demonstrating a delay in the recognition of this disease yet, which morbimortality is high $[17,18]$. As there is a higher screening of the cases for which the $\mathrm{RHC}$ is indicated in the $\mathrm{PH}$ reference centers, the number of patients who were not definitely diagnosed with $\mathrm{PH}$ was very small $(5,2 \%)$.

\section{Comparison between echocardiographic and invasive hemodynamic measurements of pulmonary pressure}

The accuracy of the TTE in providing the diagnosis of PH has been evaluated since the 80's, as it is a largely available, low-cost, non-invasive procedure. Yock and Popp (1984) demonstrated a good correlation of the measurement of SPAP by modified Bernoulli's equation between the TTE and the RHC in 54 patients $(r=0.93, \mathrm{SEE}=8 \mathrm{mmHg})$ [21]. Other authors have also demonstrated a strong correlation between these measurements [22-24].

However, the agreement between two measurements evaluated by the usual correlation methods can be inaccurate [12]. Fisher et al used the Bland-Altman method that is considered more appropriate for accuracy measurements and found a significant bias of the TTE to estimate the SPAP $(-0,6 \mathrm{mmHg}$; range of $95 \%$ agreement: -40.0 to $38.8 \mathrm{mmHg}$ ) in 65 patients within a maximum one-hour interval between TTE and $\mathrm{RHC}$ [5]. Other two studies have reported similar results with the bias ranging from $2.2 \mathrm{mmHg}$ to $8 \mathrm{mmHg}$ in the estimation of SPAP by TTE (range of $95 \%$ agreement: -34.2 to $38.6 \mathrm{mmHg}$ and -28.4 to $44.4 \mathrm{mmHg}$ ) as compared to the RHC measures $[6,7]$. Data from the REVEAL registry showed a low accuracy of the initial TTE in $57.4 \%$ of sPAP estimates $(>10 \mathrm{mmHg}$ higher or lower than RHC) and in $36.5 \%$ of RAP estimates ( $>5 \mathrm{mmHg}$ higher or lower than RHC) in examinations made within a maximum 12-month interval [7]. 
Other authors have demonstrated a better agreement between measurements of sPAP, but the level of agreement on the difference on the mean rather was large, indicating just moderate precision of the echocardiographic measurements [25-28]. D'Alto $\mathrm{M}$ et al found no significant bias $(-0,5 \mathrm{mmHg})$ between TTE and RHC estimates of SPAP with wide limits of agreement $(-19 \mathrm{mmHg}$ to $18 \mathrm{mmHg})$ [25]. Differently from other studies, RHC was indicated for reasons other than PAH (PAH: 36\%; pulmonary venous hypertension: 40\%; lung disease $\mathrm{PH}: 16 \%)$. Greiner et al have made a retrospective, single-center study including a larger sample of patients $(n=1695)$ and a maximum of 5 days interval between the examinations indicated due left heart disease (59\%), valve disease (27\%) and PAH (6\%) [26]. They found a mean SPAP of $45.3 \pm 15.5 \mathrm{mmHg}$ by TTE and $47.4 \pm 16.4 \mathrm{mmHg}$ by RHC, showing a strong correlation between measurements of $\operatorname{sPAP}(r=0.87 ; p<0.0001)$ and RAP $(r=0.82 ; p<0.0001)$. The Bland-Altman analysis has shown a $-2 \mathrm{mmHg}$ bias for SPAP (95\% agreement limits: -18.1 for $14.1 \mathrm{mmHg}$ ) and a $1 \mathrm{mmHg}$ bias for RAP (95\% agreement limits: 0.1 for $1.9 \mathrm{mmHg}$ ) [26]. Doutreleau et al have studied prospectively 106 patients with suspected or confirmed $\mathrm{PH}$, simultaneously submitted to both methods [27]. PH was not confirmed in $16.9 \%$ of the patients, $10.4 \%$ were diagnosed with post-capillary $\mathrm{PH}$ and $72.7 \%$ with pre-capillary PH. The correlations were strong (for SPAP: $r=0.84$; for RAP: $r=0.70$ ) and the Bland-Altman analysis showed a significant bias of $1.4 \mathrm{mmHg}$ for SPAP (range of $95 \%$ agreement: -22.6 to $25.4 \mathrm{mmHg}$ ) and $1.9 \mathrm{mmHg}$ for RAP (range of $95 \%$ agreement: -6.1 to $9.9 \mathrm{mmHg}$ ) [27]. Another study included consecutive patients with indication of RHC (PAH and CTEPH: 40\%; heart failure: $42 \%$ ) and a maximal of 3 hours interval between TTE and invasive measurements, revealed too minimal bias (mean bias $=+2,4 \mathrm{mmHg}$ ) between echocardiographic and invasive sPAP measure, but with wide limits of agreement $(-20$ to $+25 \mathrm{mmHg})[28]$.

Three meta-analysis and a systematic review evaluated the accuracy of the estimation of SPAP by TTE [29-32]. However, the findings were not consistent because a significant heterogeneity among these studies due to inclusion of participants without disease, other with left and right heart disease, and to the use of correlation analysis by most of them, which is less appropriate as an agreement measurement.

Although the non-invasive evaluation by TTE is recommended by current guidelines, the agreement between these methods is still debated. As far as we know, no published Brazilian study has made this evaluation in adult patients with suspected diagnosis of PAH and CTEPH in the context of daily clinical practice. The present study showed a high discriminatory power of the SPAP and TRV measured by the TTE to diagnosis of $\mathrm{PH}$, although the cut-off points of $48 \mathrm{mmHg}$ for SPAP and $3.08 \mathrm{~m} / \mathrm{s}$ for TRV have low NPV, which would limit them as screening values. Besides that, it showed a statistically significant bias for SPAP (8.0; limits of agreement:-34.9 to 50.9) and for RAP (-3.3; limits of agreement:-15.9 to 9.3). There was lesser variability between the duplicated measurements for SPAP $(C V=26 \%)$ than between those for RAP $(C V=57 \%)$. By using a clinically acceptable difference of $10 \mathrm{mmHg}$ for sPAP and $5 \mathrm{mmHg}$ for RAP, only $33.4 \%$ of the echocardiographic estimate of SPAP and $55.1 \%$ of that for RAP were accurate, similarly to the results found by Fisher et al [5] (SPAP: 52\%), Rich et al [6] (SPAP: 49.4\%) and REVEAL analysis [7] (sPAP: $42.6 \%$ and RAP: $63.5 \%$ ). This was in disagreement with the prospective study developed by Doutreleau et al [27] and Venkateshvaran et al [28], in which the measurements of sPAP were accurate in $68 \%$ and $62 \%$ of the patients, respectively and the measurements of RAP in $79 \%$ of the patients [27]. 
Additionally, in present study the TTE underestimated the SPAP values and overestimated the RAP values with higher frequency (sPAP: $41.5 \%$ versus $25.1 \%$; RAP: $33.7 \%$ versus $11.2 \%$ ) and magnitude (sPAP: -30.4 \pm 10.2 versus $15.2 \pm 8.9 \mathrm{mmHg}$; RAP: $11.3 \pm 4.8$ versus $-8.4 \pm 3.7 \mathrm{mmHg}$ ), with disagreeing values higher than $10 \mathrm{mmHg}$ and $5 \mathrm{mmHg}$, respectively. Fisher et al have found no difference in this frequency, but the SPAP values have been more underestimated than overestimated $(-30 \pm 16$ versus $19 \pm 11 \mathrm{mmHg} ; p=0.03)$ [5]. Data from Rich et al [6] and REVEAL registry [7] have also demonstrated that SPAP values were underestimated by $30 \%$ and $20.6 \%$ in the TTE and by $34.8 \%$ and $22.5 \%$, respectively, and overestimated RAP values (26.3\% versus $12.4 \%$ ) [7]. These results illustrate how difficult it is to evaluate the severity of the $\mathrm{PH}$ and to stratify its risk using TTE, since the invasive RAP obtained by RHC is a well known prognostic variable $[3,28,33]$.

The limitations of this study should be taken into consideration. As it is an observational cross-sectional study, the TTE and RHC examinations have not been performed simultaneously, but at a 3.3month average interval between them, within the context of the clinical practice regulated by the local public health authority. This way, the expected variability between equipment used and examiners should be taken into account, once the TTE examinations have been performed in different SUS's cardiology units. However, this study had the purpose of evaluating the consistency of the TTE as a screening test for the diagnosis of $\mathrm{PH}$ out of the controlled research environment. In view of that, a result lower than those reported in the literature was expected. So, these results are important as they express the differences between measurements by both methods and reflect limitations of the methods themselves, patient characteristics and the expertise of operators in the local current practice of diagnosis of $\mathrm{PH}[4,10,32]$.

As a conclusion, the initial echocardiographic evaluation of patients with suspected of $\mathrm{PH}$ in the context of clinical practice showed a high discriminatory power for diagnosis of $\mathrm{PH}$ and the disagreements between SPAP and RAP measurements reinforces TTE as a valid screening tool and the need of RHC measurements to confirm the diagnosis. The technical improvement of these procedures and a better interaction among the professionals involved in the evaluation of these patients may contribute to an even better accuracy of the TTE for an earlier recognition of this condition.

\section{Declarations}

\section{Funding:}

Not applicable

\section{Conflict of interests:}

All authors have no potential conflicts of interest related to this work.

\section{Availability of data and material:}

Data that support the findings of this study are available from the corresponding author (RAC) upon reasonable request. 
Code availability:

Not applicable

\section{Authors' contributions:}

All authors contributed to the study conception and design, data collection, analysis, manuscript writing and approved the final version.

\section{Ethics approval:}

The study has been approved by UFMG's Research Ethics Committee (ETIC nr. 1.057.219/2015).

\section{Informed consent:}

All participants provided written informed consent.

\section{References}

1. Simonneau G, Montani D, Celermajer DS, Denton CP, Gatzoulis MA, Krowka M, Williams PG, Souza R (2019) Haemodynamic definitions and updated clinical classification of pulmonary hypertension. Eur Respir J 53:1801-913. https://doi.org/10.1183/13993003.01913-2018

2. Vonk-Noordegraaf A, Chin KM, Haddad F, Hassoun PM, Hemmes AR, Hopkins SR, Kawut SM, Langleben D, Lumens J, Naeije R (2019) Pathophysiology of the right ventricle and of the pulmonary circulation in pulmonary hypertension: an update. Eur Respir J 53:1801-900. https://doi.org/10.1183/13993003.01900-2018

3. Galiè N, Humbert M, Vachiery JL, Gibbs S, Lang I, Torbicki A,Simonneau G, Peacock A, VonkNoordegraaf A, Beghetti M, Ghofrani A, Sanchez MAG, Hansmann G, Klepetko W, Lancellotti P, Matucci M, McDonagh T, Pierard LA, Trindade PT, Zompatori M, Hoeper M (2015) ESC/ERS Guidelines for the diagnosis and treatment of pulmonary hypertension: The Joint Task Force for the Diagnosis and Treatment of Pulmonary Hypertension of the European Society of Cardiology (ESC) and the European Respiratory Society (ERS): Endorsed by: Association for European Paediatric and Congenital Cardiology (AEPC), International Society for Heart and Lung Transplantation (ISHLT). Eur Respir J 46:903-75. https://doi.org/10.1183/13993003.01032-2015

4. Rudski LG, Lai WW, Afilalo J, Hua L, Handschumacher MD, Chandrasekaran K, Solomon SD, Louie EK, Schiller NB (2010) Guidelines for the echocardiographic assessment of the right heart in adults: a report from the American Society of Echocardiography endorsed by the European Association of Echocardiography, a registered branch of the European Society of Cardiology, and the Canadian Society of Echocardiography. J Am Soc Echocardiogr 23:685-713. https://doi.org/10.1016/j.echo.2010.05.01

5. Fisher MR, Forfia PR, Chamera E, Housten-Harris T, Champion HC, Girgis RE,Corretti MC, Hassoun PM (2009) Accuracy of Doppler echocardiography in the hemodynamic assessment of pulmonary 
hypertension. Am J Respir Crit Care Med 179:615-21. https://doi.org/10.1164/rccm.200811-16910C

6. Rich JD, Shah SJ, Swamy RS, Kamp A, Rich S (2011) Inaccuracy of Doppler echocardiographic estimates of pulmonary artery pressures in patients with pulmonary hypertension: implications for clinical practice. Chest 139:988-93. https://doi.org/10.1378/chest.10-1269

7. Farber HW, Foreman AJ, Miller DP, McGoon MD (2011) REVEAL Registry: correlation of right heart catheterization and echocardiography in patients with pulmonary arterial hypertension. Congest Heart Fail 17:56-63. https://doi.org/10.1111/j.1751-7133.2010.00202.x

8. Saturni S, Bellini F, Braido F, Paggiaro P, Sanduzzi A, Scichilone N, Santus PA, Morandi L, Papi A (2014) Randomized controlled trials and real life studies. Approaches and methodologies: a clinical point of view. Pulm Pharmacol Ther 27:129-38. https://doi.org/10.1016/j.pupt.2014.01.005

9. Roland M, Torgerson DJ (1998) What are pragmatic trials? BMJ 316:285. https://doi.org/10.1136/bmj.316.7127.285

10. Lang RM, Badano LP, Mor-Avi V, Afilalo J, Armstrong A, Ernande L, Flachskampf FA, Foster E, Goldstein SA, Kuznetsova T, Lancellotti P, Muraru D, Picard MH, Rietzschel ER, Rudski L, Spencer KT, Tsang W, Voigt JU (2015) Recommendations for cardiac chamber quantification by echocardiography in adults: an update from the American Society of Echocardiography and the European Association of Cardiovascular Imaging. J Am Soc Echocardiogr 28:1-39.e14. https://doi.org/10.1016/j.echo.2014.10.003

11. Rosenkranz S, Preston IR (2015) Right heart catheterisation: best practice and pitfalls in pulmonary hypertension. European Respiratory Review 24:642-52. https://doi.org/10.1183/16000617.00622015

12. Bland JM, Altman DG (1986) Statistical methods for assessing agreement between two methods of clinical measurement. Lancet 1:307-10.https://doi.org/10.1016/S0140-6736(86)90837-8

13. Bland JM,Altman DG (1999) Measuring agreement in method comparison studies. Stat Methods Med Res 8:135-60. https://doi.org/10.1177/096228029900800204

14. de Vet HC, Terwee CB, Knol DL, Bouter LM (2006) When to use agreement versus reliability measures. J Clin Epidemio I59:1033-9. https://doi.org/10.1016/j.jclinepi.2005.10.015

15. Gall H, Yogeswaran A, Fuge J, Sommer N, Grimminger F, Seeger W,Olsson KM, Hoeper MM, Richter MJ, Tello K, Ghofrani HA (2021) Validity of echocardiographic tricuspid regurgitation gradient to screen for new definition of pulmonary hypertension. EClinicalMedicine 34:100822. https://doi.org/10.1016/j.eclinm.2021.100822

16. Knafl D, Gerges C, King CH, Humbert M, Bustinduy AL (2020) Schistosomiasis-associated pulmonary arterial hypertension: a systematic review. Eur Respir Rev 29:190089. https://doi.org/10.1183/16000617.0089-2019

17. Frost AE, Badesch DB, Barst RJ, Benza RL, Elliot CG, Farber HW,Krichman A, Liou TG, Raskob GE, Wason P, Feldkircher K, Turner M, McGoon MD (2011) The changing picture of patients with pulmonary arterial hypertension in the United States. How REVEAL differs from historic and non-US Contemporary Registries. CHEST 139:128-37. https://doi.org/10.1378/chest.10-0075 
18. McGoon MD, Benza RL, Escribano-Subias P, Jiang X, Miller DP, Peacock AJ, Pepke-Zaba J, Pulido T, Rich S, Rosenkranz S, Suissa S, Humbert M (2013) Pulmonary arterial hypertension: epidemiology and registries. J Am Coll Cardiol 62:D51-9. https://doi.org/10.1016/j.jacc.2013.10.023

19. Hoeper MM, Humbert M, Souza R, Idrees M, Kawut SM, Sliwa-Hahnle K, Jing ZC, Gibbs JS (2016) A global view of pulmonary hypertension. Lancet Respir Med 4:306-22. https://doi.org/10.1016/S22132600(15)00543-3.

20. Lapa MS, Ferreira EVM, Jardim C, Martins BCS, Arakaki JSO, Souza R (2006) Clinical characteristics of pulmonary hypertension patients in two reference centers in the city of Sao Paulo. Rev Assoc Med Bras 52:139-43. https://doi.org/10.1590/s0104-42302006000300012

21. Yock PG, Popp RL (1984) Noninvasive estimation of right ventricular systolic pressure by Doppler ultrasound in patients with tricuspid regurgitation.Circulation 70:657-62. https://doi.org/10.1161/01.cir.70.4.657

22. Berger M, Haimowitz A, Van Tosh A, Berdoff RL, Goldberg E (1985) Quantitative assessment of pulmonary hypertension in patients with tricuspid regurgitation using continuous wave Doppler ultrasound. J Am Coll Cardiol 6:359-65. https://doi.org/10.1016/s0735-1097(85)80172-8

23. Currie PJ, Seward JB, Chan KL, Fyfe DA, Hagler DJ, Mair DD, Reeder GS, Nishimura RA, Tajik AJ (1985) Continuous wave Doppler determination of right ventricular pressure: a simultaneous Doppler-catheterization study in 127 patients. J Am Coll Cardiol 6:750-6. https://doi.org/10.1016/s0735-1097(85)80477-0

24. Vazquez de Prada JA, Ruano J, Martin-Duran R, Larman M, Zueco J, Ortiz de Murua JA, Torres A, Figueroa A (1987) Noninvasive determination of pulmonary arterial systolic pressure by continuous wave Doppler. Int J Cardiol 16:177-84. https://doi.org/10.1016/0167-5273(87)90249-x

25. D'Alto M, Romeo E, Argiento P, D'Andrea A, Vanderpool R, Correra A, Bossone E, Sarubbi B, Calabrò R, Russo MG, Naeije R (2013) Accuracy and precision of echocardiography versus right heart catheterization for the assessment of pulmonary hypertension. Int J Cardiol 168(4):4058-62. https://doi.org/10.1016/j.ijcard.2013.07.005

26. Greiner S, Jud A, Aurich M, Hess A, Hilbel T, Hardt S, Katus HA, Mereles D (2014) Reliability of noninvasive assessment of systolic pulmonary artery pressure by Doppler echocardiography compared to right heart catheterization: analysis in a large patient population. J Am Heart Assoc 3:e001103. https://doi.org/10.1161/JAHA.114.001103

27. Doutreleau S, Canuet M, Enache I, Di Marco P, Lonsdorfer E, Oswald-Mammoser M, Charloux A (2016) Right heart hemodynamics in pulmonary hypertension - an echocardiography and catheterization study. Circ J 80:2019-25. https://doi.org/10.1253/circj.CJ-16-0206

28. Venkateshvaran A, Seidova N, Tureli HO, Kjellström B, Lund LH, Tossavainen E, Lindquist P (2021) Accuracy of echocardiographic estimates os pulmonary artery pressures in pulmonary hypertension: insights from the KARUM hemodynamic database. Int J Cardiovasc Imaging. Epub ahead of print. https://doi.org/10.1007/s10554-021-02315-y 
29. Zhang RF, Zhou L, Ma GF, Shao FC, Wu XH, Ying KJ. Diagnostic value of transthoracic Doppler echocardiography in pulmonary hypertension: a meta-analysis. Am J Hypertens 23:1261-4. https://doi.org/10.1038/ajh.2010.188

30. Janda S, Shahidi N, Gin K, Swiston J (2011) Diagnostic accuracy of echocardiography for pulmonary hypertension: a systematic review and meta-analysis. Heart 97:612-22. https://doi.org/doi:10.1136/hrt.2010.212084

31. Taleb M, Khuder S, Tinkel J, Khouri SJ (2013) The diagnostic accuracy of Doppler echocardiography in assessment of pulmonary artery systolic pressure: a meta-analysis. Echocardiography 30:258-65. https://doi.org/10.1111/echo.12061

32. Finkelhor RS, Lewis SA, Pillai D (2015) Limitations and strengths of doppler/echo pulmonary artery systolic pressure-right heart catheterization correlations: a systematic literature review. Echocardiography 32:10-8. https://doi.org/10.1111/echo.12594

33. Ghio S, Mercurio V, Fortuni F, Forfia PR, Gall H, Ghofrani A, Mathai SC, Mazurek JA, Mukherjee M, Richter M, Scelsi L, Hassoun PM, Tello K; TAPSE in PAH investigators (2020) A comprehensive echocardiographic method for risk stratification in pulmonary arterial hypertension. Eur Respir $\mathrm{J}$ 56:2000513. https://doi.org/10.1183/13993003.00513-2020

\section{Figures}




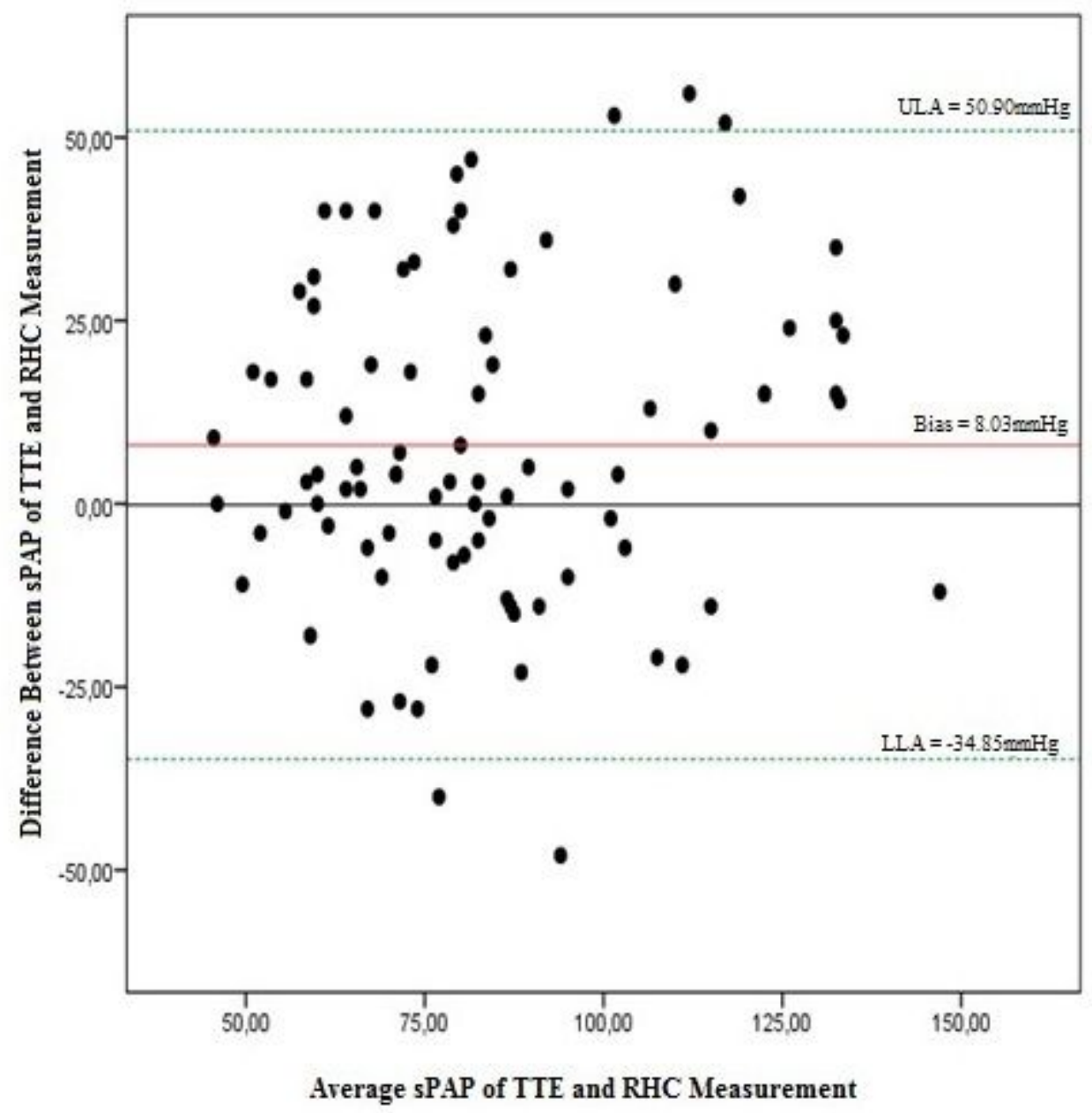

Figure 1

Bland-Altman Plot of Systolic Pulmonary Arterial Pressure Measured on Transthoracic Echocardiogram and Right Heart Catheterization. LLA: lower limit of agreement; sPAP: systolic pulmonary arterial pressure; RHC: right heart catheterization; TTE: transthoracic echocardiogram; ULA: upper limit of agreement 


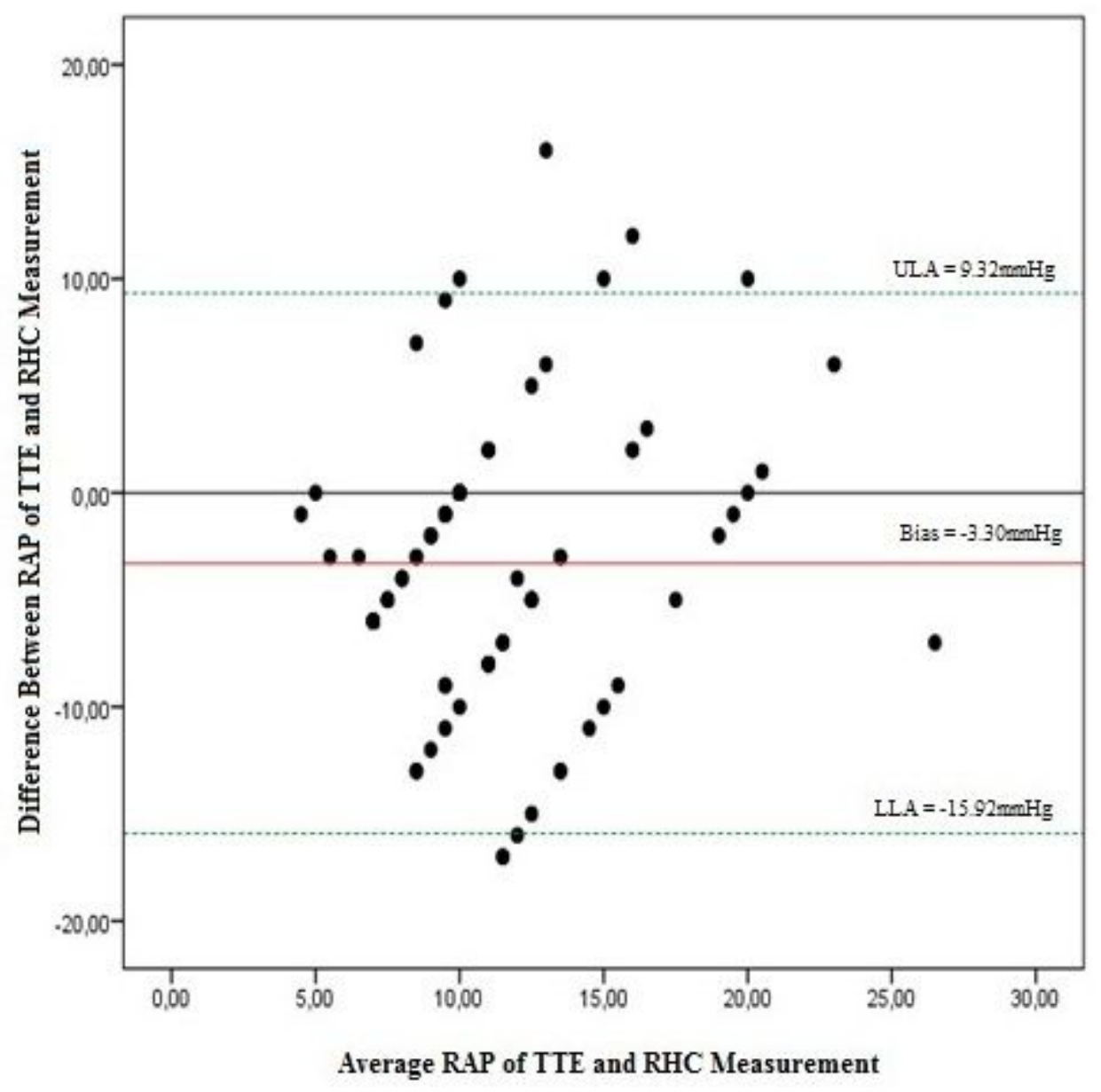

Figure 2

Bland-Altman Plot of Right Atrial Pressure Measured on Transthoracic Echocardiogram and Right Heart Catheterization. LLA: lower limit of agreement; RAP: right atrial pressure; RHC: right heart catheterization; TTE: transthoracic echocardiogram; ULA: upper limit of agreement 


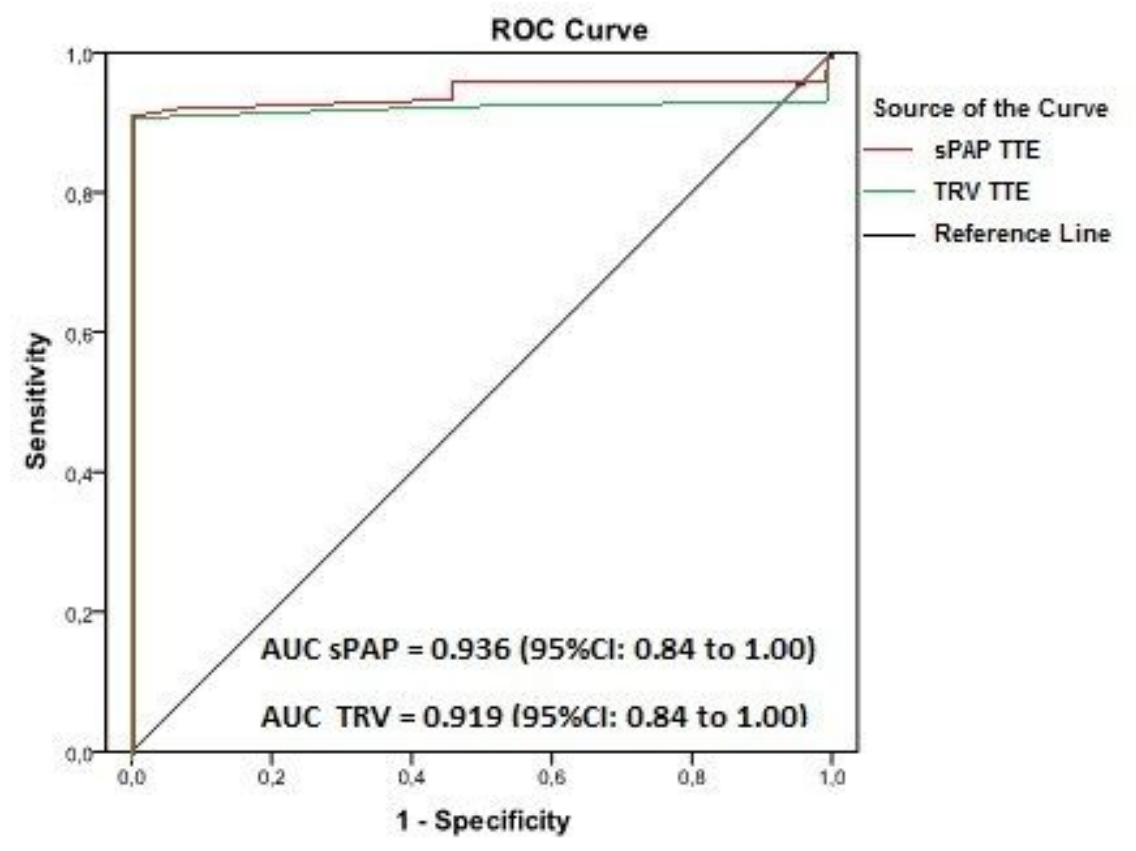

\begin{tabular}{lcccc}
\hline & Sensitivity & Specificity & PPV & NPV \\
\hline $\begin{array}{l}\text { sPAP TTE } \\
\text { (48mmHg) }\end{array}$ & $90.7 \%$ & $100 \%$ & $100 \%$ & $28.6 \%$ \\
& & & & \\
$\begin{array}{l}\text { TRV TTE } \\
(3.08 m / s)\end{array}$ & $90.7 \%$ & $100 \%$ & $100 \%$ & $33.3 \%$ \\
\hline
\end{tabular}

\section{Figure 3}

Roc Curve Analysis and Accuracy of sPAP and TRV in Transthoracic Echocardiogram to Predict Pulmonary Hypertension. AUC: area under the curve; NPV: negative predictive value; PPV: positive predictive value; SPAP: systolic pulmonary arterial pressure; TRV: tricuspid regurgitation velocity; TTE: transthoracic echocardiogram. 


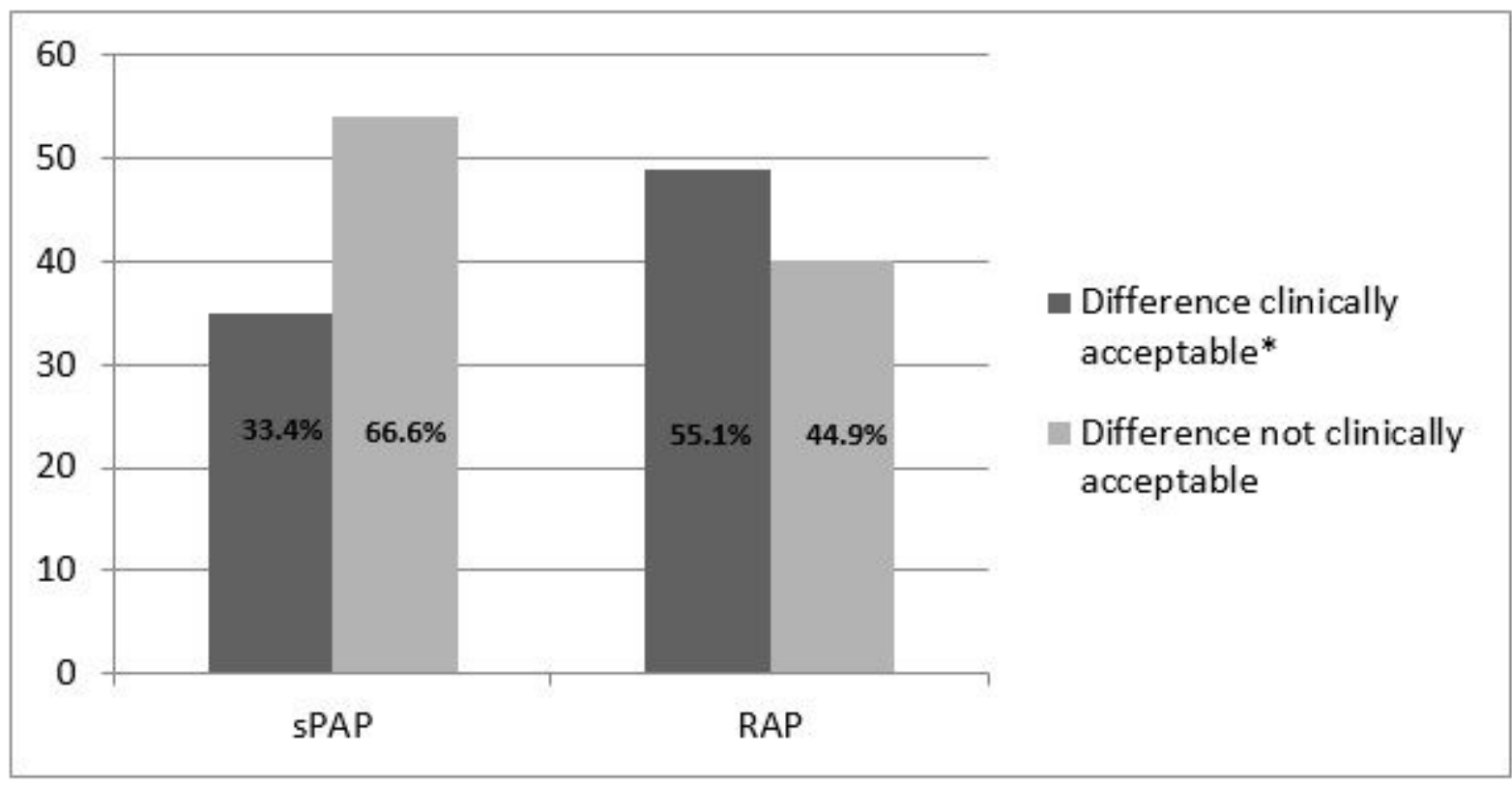

\section{Figure 4}

Differences Clinically Acceptable for SPAP and RAP Between the Transthoracic Echocardiogram and the Right Heart Catheterization. sPAP: systolic pulmonary arterial pressure; RAP: right atrial pressure. *Differences of $5 \mathrm{mmHg}$ for RAP and $10 \mathrm{mmHg}$ for SPAP between the transthoracic echocardiogram and the right heart catheterization have been considered as clinically acceptable.

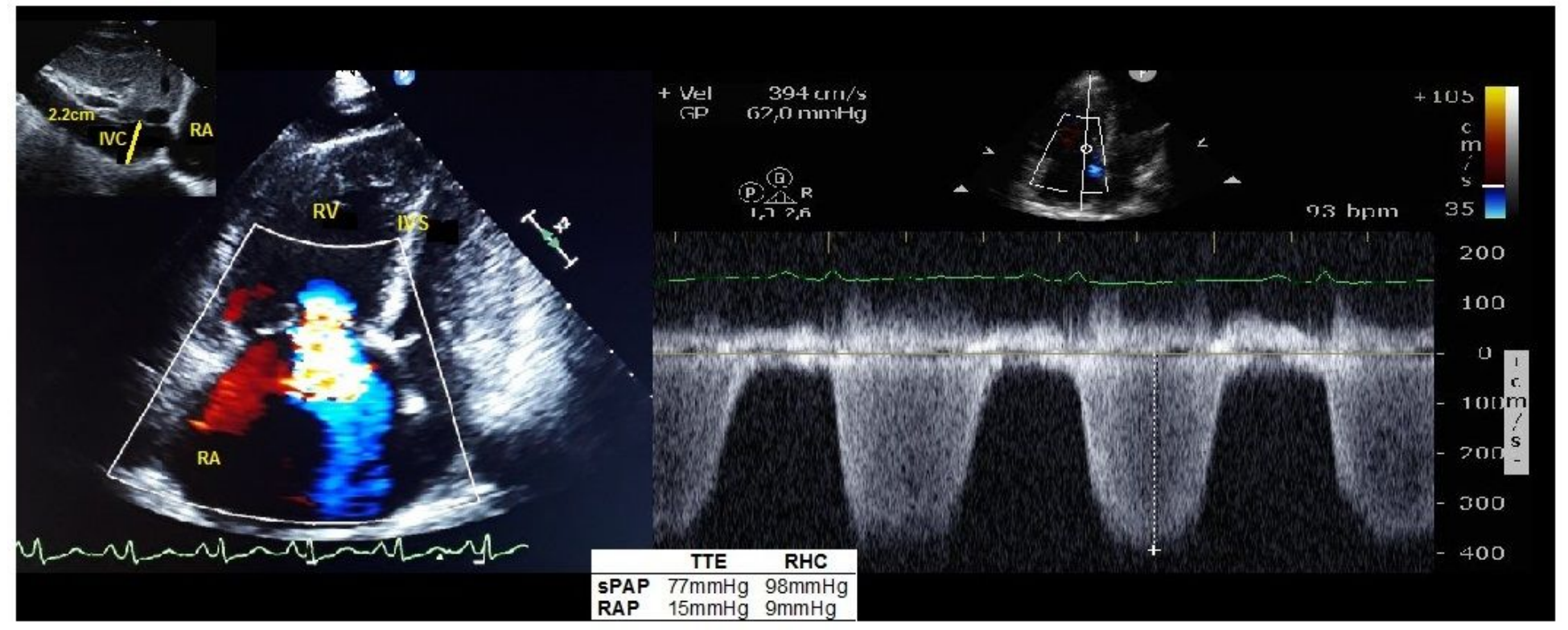

\section{Figure 5}

Disagreement Between Systolic Pulmonary Artery Pressure and Right Atrial Pressure Measurements Performed Using TTE and RHC in a Patient with Schistosomiasis Associated Pulmonary Hypertension. IVC: inferior vena cava; IVS: interventricular septum; RA: right atrium; RHC: right heart catheterization; RV: right ventricle; SPAP: systolic pulmonary arterial pressure; TTE: transthoracic echocardiogram. 